\title{
Teaching For Justice: Introducing Translanguaging in an Undergraduate TESOL Course
}

\author{
Elizabeth Robinson \\ Suffolk University \\ Correspondence concerning this article should be addressed to Elizabeth Robinson, Suffolk University, 8 \\ Ashburton Pl, Boston, MA 02108, USA.E-mail: erobinson@suffolk.edu \\ Zhongfeng Tian \\ Boston College \\ Correspondence concerning this article should be addressed to Zhongfeng Tian, Curriculum \& \\ Instruction, Boston College, 140 Commonwealth Avenue, Chestnut Hill, MA 02467, USA. \\ E-mail:tianza@bc.edu
}

\section{Tiffany Martínez \\ Columbia University}

Correspondence concerning this article should be addressed to Tiffany Martínez, Graduate Sociology Major, Columbia University, 715 North Ave, New Rochelle, NY, USA.E-mail: tiffany2695@gmail.com

\section{Aybahar Qarqeen}

Suffolk University

\begin{abstract}
Correspondence concerning this article should be addressed to Aybahar Qarqeen, Undergraduate Psychology Major, Suffolk University, Psychology Department, 73 Tremont Street, Boston, MA 02108 USA. E-mail: bahara.9600@gmail.com
\end{abstract}

\begin{abstract}
This study investigates how introducing translanguaging as a way to affirm language and culture impacted students' understandings of learning and teaching in a TESOL certificate course offered at a university in the northeast of the United States. As researchers, teachers, and students committed to justice, we explored the impact of introducing translanguaging in a course that was originally designed as a Sheltered English Immersion (SEI) course through collaborative, qualitative approaches of thematic analysis and macro- and micro-level analyses of power based on our unique individual experiences in the classroom. We found across our analysis that introducing translanguaging provided opportunities to shift assumptions and that, overall, students demonstrated critical sociocultural understandings of language that are foundational in teaching for justice. Ultimately, while we recognize the need for more explicit discussion about the purpose and pedagogy of translanguaging, the shifts towards teaching and embracing multilingual and multicultural realities through translanguaging which the study identified can contribute to the field of language education by demonstrating how teachers might open up possibilities in teaching for justice.
\end{abstract}

Keywords: translanguaging, justice, TESOL, teacher preparation, collaborative research, language teaching and learning

In the midst of a complex and racially tense political climate, educators must hold one another accountable for the oppressive power structures embedded in academic institutions that fail to affirm all identities. The demographiclandscape, in the context of theUnited States of America, is changing at an unprecedented rate, especially in terms of ethnic and racial diversity.
The fastest growing student population in the United States today is children of immigrants, half of whom do not speak English fluently (Calderón, Slavin, \& Sánchez, 2011). The persistent academic attainment gaps experienced by these students highlight the insistent and indefatigable need for culturally sustaining (Paris, 2012) English instruction models. 
Currently, Sheltered English Immersion(SEI) programs serve as a frequently mandated language instruction model in the United States where participating classrooms enforce an English-only policy rather than including the linguistic diversity of learners. As researchers, educators, and students we argue that an alternative model of English instruction exists that does not prioritize assimilation or the erasure of non-English languages in the classroom. Committed to cultivating culturally- sustaining classrooms, we believe translanguaging provides the theoretical and pedagogical tools vital to challenge these structures. It holds the promise of shifting traditional language instruction frameworks and providing us with tools to teach language for justice (Ladson-Billings, 2015).

Theoretically, translanguaging refers to the dynamic process of strategically and creatively selecting linguistic features from one unitary, complex linguistic repertoire to make meaning (García \& Li Wei, 2014; Otheguy, García, \& Reid, 2015). Pedagogically, translanguaging promotes ways for students and teachers to engage in complex and fluid discursive practices that strategically include the home language practices of students in classroom meaning-making activities (García, 2014). Therefore, byvaluing students' linguistic knowledge as assets rather than burdens and leveraging their full linguistic repertoires in academic learning, translanguaging counters the monoglossic American classrooms by opening up inclusive spaces for the development of multilingualism.

We view translanguaging as a tool for teaching for justice because it holds the potential to challenge the dominance of English and the traditional power dynamics in U.S. classrooms. In a translanguaging classroom, language learners are not situated as deficient non-natives, but as "resourceful" agents (e.g., Pennycook, 2012, p. 99) with multilingual repertoires and abilities for successful communication (Canagarajah, 2014). Also, learners are afforded more agency and opportunity to become co-producers of knowledge rather than exclusive consumers of knowledge. Therefore, each individual in the classroom, including the teacher, is set to learn from each other. By exchanging ideas and learning from one another across cultures, races, and ethnicities, the nature of English-only instruction on colonized land is challenged and less U.S. centric.

In this article, we examine the impact of introducing translanguaging in a Teachers of English to Speakers of Other Languages (TESOL) certificate course. In an effort to conduct this study with an intersectional lens, as researchers we are diverse in age, race, language, ethnicity, citizenship status, and have various levels of academic attainment. At each of our cores, we believe in the power of collaborative learning and sharing agency in academic spaces. We see our work as a response to the recent call for pedagogy that develops and makes use of students' full range of language and literacy skills (Orr \& Annous, 2018). Our study of translanguaging aims to export our passion for teaching for justice into research and classrooms around the world.

The purpose of our study is to explore the pedagogical and theoretical implications of introducing translanguaging in an undergraduate TESOL course originally designed as a SEI course offered at an undergraduate institution in Boston, U.S.A. We want to explore how translanguaging might help prepare teachers to teach for justice. The research question driving this study is: How does introducing translanguaging impact students' understandings of learning and teaching in a TESOL certificate course?

\section{Conceptual Framework}

Translanguaging, as the major conceptual framework undergirding our study, can be understood from two perspectives: translanguaging as theory and translanguaging as pedagogy. Translanguaging as a theory (García \& Li Wei, 2014) centers not on languages but on the observable, natural communicative practices of bilinguals. It interrogates the duality of bilingualism and posits bi/multilingualism as fluid and dynamic: there are not two or more separate and bounded systems of languages, but rather one single linguistic repertoire from which individual speakers strategically select and deploy features to accomplish different communicative and expressive ends (García \& Li Wei, 2014; Otheguy, García, \& Reid, 2015; Vogel \& García, 2017). Translanguaging thus takes up an internal perspective to describe the languaging of multilingual speakers, and it aims to disrupt the socially constructed boundaries of named languages ${ }^{1}$ (such as Spanish, Mandarin, and English). It critiques the dominance of English by privileging bilingual performances and legitimizing all the varieties of language (Vogel \& García, 2017). This represents an epistemic shift from a traditionally monolingual, static view of language acquisition to a more holistic, fluid understanding of language as social practice (García, 2009).

Pedagogically, translanguaging acknowledges bi/ multilingualism as a resource. It promotes ways for students and teachers to engage in complex and fluid discursive practices that strategically include the home

\footnotetext{
At the same time, however, "translanguaging theory still recognizes the material effects of socially constructed named language categories and structuralist language ideologies ... These named languages carry different statuses and impose different social expectations and constraints upon bilinguals; thus for bilinguals, there is a 'more complex socio-cultural marking of which features to use when and where' than for monolinguals, who most often speak with the language conventions of the society in which they live (Otheguy, García, \& Reid, 2015, p. 13)" (Vogel \& García, 2017, pp. 4-6).
} 
language practices of students in classroom activities (García, 2014). Through employing multilingual/ multimodal resources, choosing culturally relevant texts, and positioning teacher as co-learner (García \& Kleyn, 2016), translanguaging creates a culturally and linguistically sustaining classroom (Paris, 2012) where all learners are encouraged to bring all their communication styles, registers, and repertoires (Makalela, 2015, p. 202) to engage in learning. Because the main objective is to learn English along with an understanding of its power, translanguaging gives students access to the dominant culture while also challenging the hegemony of standard English. Generally speaking, translanguaging as pedagogy enables a more equitable, just education for students from language-minoritized groups. Translanguaging is different both theoretically and pedagogically from SEI. Theoretically, SEI approaches learning language as best accomplished through immersion in the target language. Pedagogically, SEI is an English-only approach which does not allow other languages to be used in the classroom for instructional purposes. The goals of SEI are to develop grade-level content-area knowledge, academic skills, and increased English proficiency. In sheltered English classes, teachers use clear, direct, simple English and a wide range of scaffolding strategies to communicate meaningful input in the content area to students. While SEI promotes standardized English, translanguaging critiques the dominance of English. SEI represents an assimilationist perspective that erases students' linguistic heritages. There is an ideology of linguistic purism that undergirds English Only instructional models such as SEI (Martínez, Hikida, \& Durán, 2015). Translanguaging alternatively promotes assetbased pedagogies that incorporate learners' familiar language and cultural practices into learning (García, 2009) while also working to overtly challenge and overturn ideologies of language rooted in racist, classist, and imperialist histories of standardization (Makoni \& Pennycook, 2007).

We believe translanguaging is a vehicle for "liberating the voices of language minoritized students" (García \& Leiva, 2014, p. 200) to achieve the goal of disrupting both the dominance of English and the traditional power dynamics in the classroom. Our paper explores what this looks like both theoretically and pedagogically through a classroom case study.

\section{Materials and Methods}

\section{General background}

This is a collaborative qualitative study that drew on methods of teacher research (Cochran-Smith \& Lytle, 1993) to explore the impact of introducing translanguaging theory and pedagogy into an SEI course. As the four authors of this study, we are a professor, a doctoral student, a teaching assistant, and an undergraduate student. We designed our study to recognize the critical roles and contributions of each of the authors and drew upon our collective experience, knowledge, and wisdom.

At the time this study was conducted in Massachusetts the education policies required all teachers to be certified in Sheltered English Immersion (SEI). SEI is a teaching approach that utilizes English as the only mode of instruction to be used with English Learners. In order to obtain a license to teach in Massachusetts, all teacher candidates, regardless of their content area, needed an SEI certification. This certification could be obtained through an SEI course within a teacher preparation program or by passing a licensing test on the principles and practices of SEI.

Within this context, the course that we researched titled Strategies for Working With English Learners, had been designed in 2015 as an SEI course for a teacher preparation program offered at a city university in Massachusetts. At the end of 2015 this university closed down its teacher preparation program in part due to the increasing requirements from the state for licensing teachers. Although there was no longer a teacher preparation program, many undergraduate students at this university wanted some exposure to teaching. In 2017 a TESOL Certificate program was developed for undergraduate students. Strategies for Working with English Learners was one of the 3 required courses for the certificate.

While preparing for the TESOL Certificate program, the professor of the courses met a doctoral student from a different university in the city who was knowledgeable about translanguaging. The professor was very excited to learn about translanguaging and felt that this approach was more aligned with their goals of teaching for justice than SEI. These two authors formed a partnership with the goal of transforming the TESOL Certificate program from an SEI-based approach into a translanguaging approach. This was the beginning of our research team and we started by looking at how we might introduce translanguaging in the first course offered for the TESOL Certificate, Strategies for Working with English Learners, in the spring of 2017.

All the authors met continuously throughout the spring 2017 semester to think about ways to shift the course from an English only approach to a translanguaging approach. Using a google document we collaboratively read through the syllabus and changed language and assignments that reflected an English only approach. This collaborative rewriting process sparked many conversations about terminology, methodology and theory and strengthened our collective understanding of 
translanguaging. We then decided to introduce translanguaging in two ways. First, we taught about translanguaging as theory and pedagogy and second, we engaged in a few translanguaging practices. Introducing translanguaging as theory fit well with the critical sociocultural approach used by the professor in teaching about language acquisition and language teaching. One of the professor's learning goals was for students to develop an understanding of the role language plays in the "dynamic and dialogic power relationships between the social and individual, the global and the local, the institutional and the everyday" (Lewis \& Moje, 2003, p. 1992). Additionally, both the doctoral student and the teaching assistant gave presentations in the course about translanguaging and supporting non-dominant learners. Students were asked to reflect upon these presentations after.

The second way of introducing translanguaging was intentionally engaging students in some translanguaging practices. We made journals part of the course to allow students the space to clarify and think in any language they felt comfortable. Another translanguaging activity was learning the linguistic and cultural rituals for greetings in all the languages present in the class. These were reinforced by everyone in the class greeting every student in their home languages at the beginning of class.

\section{Participants}

All thirty undergraduate students enrolled in Strategies for working with English Language Learners in the spring semester of 2017 were informed at the beginning of the course that they had the option to participate in a research study and pseudonyms would be used to protect their identities. Fourteen of the thirty students, two males and twelve females, signed informed consents to participate in the study. The class held impressive linguistic and cultural diversity with twenty-seven languages/cultures represented. Half of the participants were English monolingual students and half were multilingual students who brought the following linguistic and cultural knowledge to the class: Chinese, Spanish, Polish, Vietnamese, Persian, Turkish, English, Arabic, Greek, German, Japanese and Hawaiian.

\section{Data Sources}

Data sources consisted of two sets of artifacts and the collective reflective experiences of the authors. The artifacts collected at the end of the semester were: students' reflective journals and students' final portfolios. For the reflective journals, students were asked to respond to a journal prompt at the beginning of most classes. The journals were designed as a place for students to freely explore concepts and their ideas about learning and teaching language. Students were encouraged to use any language they chose in their journals. The majority of students wrote in English. The journals were graded on effort as opposed to actual content. Students' final portfolios were designed as a summative assessment to showcase the learning the students were taking away from the class. The components of the final portfolios (See Appendix) were a philosophy of language statement, a model lesson plan and reflection, a classroom observation reflection, and a personal reflection on their findings of research projects identifying the educational needs of English learners. For the third data source, the authors noted and gathered reflections on experiences they had in the classroom throughout the semester.

\section{Data Analysis}

We conducted two different kinds of analysis during this study. One was thematic analysis to examine the ways in which students' understandings of language, teaching and learning were impacted by introducing translanguaging. Using principles of systematic data analysis (Halsall et al., 1998; Hubbard \& Power, 1999) we collected and organized students' artifacts from the Strategies for Working With English Learners course. Drawing upon our own multiple languages, cultures, and identities, we kept our research question in mind as we individually read through the students' coursework and assignments and inductively coded for themes. We then shared and analyzed our insights and the themes we found. Three major themes emerged during this process. They were 1 . defining language 2 . teaching language and 3 . learning language. Working together we went back through our data to find representations in students' writing of their meaning making related to each theme.

Our second type of analysis focused on power and how introducing translanguaging could support more just understandings of language, teaching and learning. Our goal for this analysis was to figure out how we could challenge dominant power structures through introducing translanguaging. In our weekly research meetings our team discussed at both a micro and macro level the implications of introducing the theory and pedagogy of translanguaging in the course. At a micro level, we reflected and shared our perspectives from our different roles in the classroom. We analyzed and planned strategies and approaches to meet challenges that arose. At a macro level, we reflected on the lessons we were learning from collectively exploring translanguaging. We discussed the implications our work might have for the field of teacher preparation, schools, higher education and the overall current political climate. The following section of this paper elaborates on the findings from these two types of analysis. The three 
themes of defining language, teaching language and learning language are explored using student quotes to exemplify students' understandings of each of the themes. We also highlight tensions and contradictions found within each theme. Finally, the micro- and macro-level lessons we have learned from introducing translanguaging are examined.

\section{Results}

\section{Defining Language}

The first important theme of defining language came from reading through journals and class assignments, and looking for the ways in which students wrote about language. The majority of students, 12 out of 14 , understood language from a functional perspective as a tool. In other words, these students wrote about the uses and functions of language. We have selected two representative quotes from students' philosophy of language statements included in their final portfolio assessment for the course.

The way that a therapist uses specific language can help facilitate the conversation in a way that the patient is perceptive to.... Also, the therapist must create a nurturing environment to a degree, in order to establish trust and a safe environment for the patient to be honest and vulnerable in order to get to the core of whatever issues that need to be addressed. (Laura)

Laura's quote demonstrates how she saw language as a tool to foster and create a productive relationship between a therapist and a patient. This concept of language as a tool for better communication in order to gain trust and ultimately do the work of counseling, was linked to Laura's professional aspirations of being a mental health counselor and therapist. As an English speaker Laura saw her language as the tool she would need to be an effective therapist. Another example of a student's recognition of the powerful function of language can be seen in Nancy's philosophy of language statement.

In financial institution industry, language is one of the most important skill which make people be able to networking, marketing yourself and gain knowledge in your long career path. (Nancy)

Nancy specifically wrote about language as a skill. She recognized that many of the activities required to be successful in the financial field required strong language skills. As an emergent English learner, Nancy was very aware of the need to develop the skills she identified for her career in English. Both Laura and Nancy recognized language as a necessary tool for

\section{their future careers.}

Some students, 5 out of 14, wrote about language as being connected to culture and identity. We believe this expression of language relates to the sociocultural perspectives and theories that were taught in our class and other Education classes. These five students were all Education minors and had been exposed through multiple classes to sociocultural theories. The professors in the Education program believe in and teach the importance of language in producing and reproducing ways of knowing, acting and doing. In particular we take a critical stance and pay particular attention to the power and role of language in constructing and re-constructing inequalities through social, institutional and systemic relations (Bourdieu \& Passeron, 1977; Fairclough, 1989; Foucault, 1980; Pennycook, 2001).

The quotes of students who wrote about language as related to society and culture demonstrate a more complex understanding of language than just serving as a tool for communication. We do not see a tension between a functional and sociocultural understanding of language, many students held both. Rather, we see the possibilities for broadening students understandings of the interconnectedness of language, culture and identity.

My culture and language have a huge impact on my identity. The way I speak, I talk, and communicate with others as well as my behaviors and beliefs comes from my culture and my language. I could see this visibly when I moved to the US. (Adriana)

Adriana wrote about this interconnectedness in one of her weekly journal entries. She recognized that not only the way she acted (behaviors), but also how she thought (beliefs), were constructed through her language and culture. She was an ELL with proficient access to multiple named languages, and most of her academic experience came from outside of the US. It was not surprising to us that Adriana easily understood the concept of translanguaging and could point to her own experiences and practices as examples. However, it was not only "multilingual" students who understood translanguaging and had a sociocultural understanding of language.

Laura, who above wrote about language as a tool for building relationships, was also able to hold both a functional and sociocultural understanding of language.

Language gives people their own identity and comes with a world of cultures and traditions and this should be celebrated and embraced, because if I've learned anything from this class, it is that we can learn so much just by talking.(Laura)

The verbs Laura used in her her journal entry, show her understanding that language has the ability and the power to give or construct identity. From analyzing the ways that students wrote about 
and defined language, we realized that introducing translanguaging provided opportunities for the students to examine their definitions of language. For some students the introduction of translanguaging created an awareness of the power of language beyond just a tool for communication. Making the link between language and culture and broadening the conceptions of language to consider multiperspectivity and bi/ multilingualism deepened appreciation of language for some students.

\section{Teaching Language}

Our second theme is teaching language. Nearly all the students recognized the pedagogical promise of translanguaging: it is important and necessary to implement translanguaging in language teaching classrooms. Students have demonstrated multiple understandings of the merits held by translanguaging as pedagogy. Here we have selected four representative quotes from students' reflective journals when they had been asked to reflect on what they had learned about translanguaging.

It is very important to have, because it provides a background and diverse culture for new generations. It is a way to value and respect everyone. (Luna)

Luna said that translanguaging could be used as a pedagogical tool to "value and respect" cultural diversity in classrooms. Students (as "new generations" in Luna's words) in such classrooms can benefit from learning each other's rich cultural background and knowledge. Luna here understood that translanguaging has the potential of creating a multicultural environment.

Translanguaging is something I think is very important. If the concept was more implemented in schools, I think it would raise the knowledge and eventually benefit all learners. Maybe individuals who didn't plan on ever being bilingual could then get the opportunity to learn another language not only from a teacher but from peers in the school system. (Anna)

Anna pointed out that by allowing students to bring their home languages (their entire linguistic repertoires) into classrooms, the classroom will become a multilingual site where all students could get the opportunity to learn each other's language. Monolingual students ("individuals who didn't plan on ever being bilingual") could also benefit from this process by hearing a variety of languages and interacting with their multilingual peers. In addition,
Anna emphasized that translanguaging can turn a classroom into a learning community in which everyone is a knowledge resource ("not only from a teacher but from peers").

I think this is an extremely great model and way of thinking. In a world where there is constantly a fight for power it is refreshing to see that shift away from in classrooms. Students no matter their language or color or whatever else should be comfortable in the classroom. ... Students shouldn't be stripped from their identities in our education system. Who knows maybe if translanguaging is used in the classroom all over the nation, a lot of our social/civil/political issues would be solved. (Laura)

Laura saw translanguaging from another perspective, i.e., a social justice orientation. According to her, first, translanguaging in classrooms can affirm everyone's identity regardless of their language, race, or ethnicity. Translanguaging holds the promise of creating a comfortable, inclusive context of learning for all students. Second, moving beyond classrooms to the whole nation, translanguaging could disrupt the dominant power structure and then "a lot of our social/civil/political issues would be solved". Generally speaking, Laura believed that translanguaging represents "a great model and way of thinking", and provides a viable solution to address inequality issues to make our society more just and equitable to people from minoritized communities.

We then learn from others and they get to talk about their culture. I find it interesting and more eye opening. We should have a good environment with others. It would be beneficial to have a global perspective. (Jane)

Jane's quote focused on the global perspective that translanguaging as pedagogy could afford students. In this culturally diverse and inclusive environment, "we then learn from others" by valuing everyone's cultural backgrounds and allowing them to "talk about their culture". To her, this is an "interesting and more eye opening" process.

To briefly summarize, students demonstrated an awareness of the multiple affordances of translanguaging as a pedagogical tool in language teaching classrooms: not only can it foster a multilingual, multicultural environment where everyone's identity (for example, culture, language, race) is affirmed and valued, but also has the potential to advocate for social justice for language-minoritized groups by challenging and disrupting the dominant power. Translanguaging as pedagogy shifted students' 
awareness of teaching from a focus on strategies for individual ELLs to broader implications towards justice for everyone, new generations, the nation and the globe.

In addition to the pedagogical promises, some students also pointed out problems facing the implementation of translanguaging in language teaching.

Translanguaging is a very interesting topic that many teachers and administrators aren't prepared for. I think it is a 'perfect world' idea but will take a lot of time to succeed in providing a firm structure within the system .... I like splitting students into groups but what if there is an uneven amount? ... Would teachers need to go to school longer?" (Luna)

Luna understood translanguaging to be an overly "perfect" approach of which the implementation will "take a lot of time to succeed" due to the lack of teacher and administrator preparation in this area (e.g., the lack of teacher training, the English-only language policy system). Also, she questioned the feasibility of the grouping strategy in a translanguaging classroom (because translanguaging as pedagogy claims that we as teachers could group students based on their similar home language backgrounds so that students are able to draw upon their entire linguistic repertoires to engage in group discussions deeply). Luna was concerned about the "uneven amount" of students in each group, which might weaken the quality of group discussion. Additionally, Luna was also pondering if "teachers need to go to school longer". Here we speculate that Luna might think that teachers need more time to learn other languages in order to perform translanguaging in a classroom (although according to the literature, e.g., García \& Kelyn, 2016, a teacher in a translanguaging classroom need not be bilingual).

How would you implement [translanguaging] with a class of students that have all different languages, none in common? (Martyna)

Martyna raised the difficulty of attending to everyone's full linguistic repertoires: what if the students all have different languages? How do we as teachers choose culturally relevant texts to take everyone's cultural and linguistic backgrounds into consideration and to resonate with everyone's experience? How do we as teachers group students based on their shared home languages when there is "none in common"? Although the scenario Martyna brought up is an extreme case, her concern is worthwhile to keep in mind when applying translanguaging teaching strategies in a culturally and linguistically diverse classroom.

\section{...We need to have good teachers. (Jane)}

Instead of a critique, Jane's words suggest the direction our next steps should take: teachers are on the frontline of implementing translanguaging as pedagogy in classrooms, thus "we need to have good teachers" in order to foster heterogeneous, meaningful, and inclusive contexts of learning for all students. We would like to endorse her idea and further point out the importance of teacher preparation, and that a translanguaging perspective should be infused throughout the teacher education program.

In summary, while recognizing the critical role of translanguaging in language teaching, students were still skeptical about translanguaging being overly idealistic. They have acknowledged the challenges of implementing translanguaging for different stakeholders, such as when none of the students share similar home languages, the lack of teacher and administrator preparation, and the potential push back from the whole educational system.

\section{Learning Language}

Our third theme focused on how students understood learning language. Most of the focus of class discussions and the writing done by students was on learning languages in addition to their home language as opposed to the process of learning a home language. We saw through most students' writing that when they wrote about learning additional languages they recognized that learning language also entailed learning culture. This was a connection between language and culture that we had not seen when we were looking at the ways students defined language. When we examined the connections between translanguaging and learning language, we found that the concept of translanguaging resonated with our bi/multilingual students' experiences of learning and using multiple languages in ways that were not demonstrated in the writing of monolingual students. Lisa, a Mandarin speaker, wrote in a journal entry about how translanguaging helped her make sense of the way she engaged with both Mandarin and English.

The translanguaging theory refresh my perception of bilingual or multilingual speakers. It explains my myth that why I always blend English and Mandarin together when I talk to someone. Sometimes I can only remember the word in English but not in Chinese, even though Chinese is my native language... According to the translanguaging theory, all the language you learned store in a overall system, therefore, all your knowledge and experience would applied when you learn another language. Older people has more social experiences and learning ability, 
which make the learning process more systematic. (Lisa)

For Lisa, it made senese that she might interchange Mandarin and English given that her language repertoire was one unitary, complex system made up of indefinite linguistic features (García \& $\mathrm{Li}$ Wei, 2014). She also reflected on language learning as building on a person's existing resources. She extrapolated from this understanding to explain how the more experiences a person has, the better and more systematic their learning is. It is interesting to note that this sociocultural understanding of learning language contradicts the often discussed monolingual assumption that languages must be learned at a young age.

Another point that several students raised in their writing about learning language is related to the injustices of English-only policies and ideas around assimilation. Students expressed that language learning should not require students to learn only English and sacrifice their home languages and cultures. Very often when approaches like SEI are used, the goal is proficiency in English and limiting or eradicating the use of home languages other than English. Students in our class felt strongly that these were not just practices.

Learning a language should not come with stripping away one's first language and culture, it should be an addition to the beauty of the plethora of languages we all speak in the world. (Sophia)

Interestingly, Sophia linked language and culture together as the components that get "stripped away" in the process of learning a language in her philosophy of language statement. When students wrote about language learning, there was a general awareness of the link between language and culture. Sophia was herself bilingual and bicultural and she promoted an additive rather than a subtractive view of bilingualism. However, it was not only bi/multilingual students who wrote about the value of learning language. Laura, a monolingual English speaker also wrote about her desire to expand her linguistic and cultural repertoires.

I hope to work on my own language development and continue to embrace the unique identities and cultures that each language I am presented with comes with. (Laura)

We realized through our analysis and discussion of students' writings about learning language that we had multiple entry points to help students recognize the connections between language, culture and power. Although not many students defined language in a sociocultural way, when writing about learning language they recognized and wrote about language as connected to culture. Introducing translanguaging helped us as researchers and teachers as well as helping the students to understand learning language as a process of strategic adaptation. Learning a language is not about assimilating to the dominant culture. Learning language is a process of understanding what linguistic features to choose as appropriate for a given context and purpose. Pedagogically, if everyone's languages, cultures and identities are valued and built upon in classrooms then learning a language becomes a culturally sustaining practice (Paris, 2012).

\section{Micro-Level Lessons}

Focusing on the pedagogy of translanguaging within the space and the practices of the classroom, we saw some ways that introducing translanguaging challenged dominant structures of power. We reflected that it was not uncommon in education classes for native English speakers to dominate classroom discussions. There was a noticeable shift in the power dynamics among the students when we introduced practices of translanguaging. We learned the linguistic and cultural greetings for each student in our class. At the beginning of each class session, we greeted everyone in their own language. The students who were native English speakers became embarrassed that they only spoke English and were greeted with "hi", while everyone looked forward to greeting students in languages other than English. This simple activity shifted the cultural capital in the classroom to the benefit of multilingual speakers by valuing and recognizing them and their linguistic resources.

As a team we also noticed that there is a need for more explicit discussion about the purpose of translanguaging. We found that most students considered translanguaging to be an overly idealistic approach. A common misperception students had was that translanguaging meant teaching and learning all the different languages in a classroom. Now that we recognize this area of confusion for students encountering translanguaging we can work to develop a deeper understanding of translanguaging.

\section{Macro-Level Lessons}

Reflecting on translanguaging as theory and how the lessons from translanguaging might transcend the classroom walls, we believe in its potential to provide teachers with a critical lens. Teachers who are able to recognize and critique the ways in which power operates to maintain dominance are better equipped to enact more just teaching. We recognize that power dynamics do not only live within classrooms. During the process of our study the political climate of our country continued to be a reminder of the necessity of learning about and from others. Making 
space in our classroom to learn, value and practice multiperspectivity helped to develop empathy and interest in the world and will, hopefully, lead to the facilitation of better intercultural communication. Analyzing students' work gave us a sense of wonder that while students acknowledged the individuality of each person, the most important takeaway from this class was mainly a deeper appreciation for our common humanity.

\section{Discussion}

Our findings demostrate that introducing translanguaging in the Strategies for Working with English Learners course was just the beginning to a process of teaching for justice, but that translanguaging helped students develop justice-based ideas of languge, teaching and learning. Students thought and wrote about the power and importance of language, the existing inequalities of current approaches to Sheltered English Instruction (SEI), and the need to affirm all identities.

We noticed a group of students who demonstrated sociocultural understandings of language and the interconnection of language, identity and culture. Related to students' understandings of teaching we found an awareness of the importance for teachers to build an inclusive learning community to incorporate students' cultural and linguistic funds of knowledge. We saw that students recognized the need for classrooms to affirm all students' identities and to position everyone as a teaching resource. We believe these are demonstrations of students developing a translanguaging stance. Developing a translanguaging stance is the first strand of a translanguaging pedagogy, which also entails building a translanguaging design and making translanguaging shifts (García, Johnson, \& Seltzer, 2017). For our students, this means building a belief system that they can draw from as teachers. All teachers must believe that students' language practices are both a resource and a right (Ruiz, 1984) and that these language practices work together and must be valued and supported to facilitate learning (García, Johnson, \& Seltzer, 2017).

In looking at students' understandings of learning language, we recognized students' awareness of the importance of maintaining home languages. We found that students were critical of models of assimilation into the English-dominant world that generally require all non-English language features, accents, and mannerisms to be discarded or hidden.To counter deficit perceptions of ELLs that often exist in Englishdominant settings, we need to ensure future teachers respect, value, and support students' non-dominant languages and cultures. Pedagogical implications from this study suggest that in future courses we need to further students' critiques of assimilation models to discuss the implications of bringing translanguaging into a TESOL context. TESOL is about teaching and learning English and recognizes and promotes the dominance of English. However, we see promise for translanguaging to contribute to the field of TESOL by shifting ideas about language and language teaching and learning and promoting culturally and linguistically sustaining practices.

Concerning our goal of teaching for justice, we saw how translanguaging had the potential to challenge the often unquestioned dominance of English and create culturally and linguistically sustaining classrooms. However, given the distinctness in our student sample, namely the fact that we have a far more diverse student composition than traditional teacher preparation programs, future research should also examine the impact of translanguaging on a more homogeneous teaching population. Traditionally, predominantly white, monolingual English speakers go into the field of teaching. As was previously said, it is of vital importance to challenge their often monoglossic ideologies and develop a translanguaging stance which values bi/multilingualism as a resource. Learning from and valuing the differences of all students is an initial step toward the work that needs to happen beyond the classroom walls. As educators and researchers, we must hold one another accountable for the injustices in our academic institutions, just as we must all hold our political institutions accountable for the harm and terror they inflict upon people through separating families, and failing to protect those in danger. We believe a future teaching force equipped with a critical lens will better serve the growing bilingual student population in the United States by providing a more just and equitable education.

\section{Conclusion}

In this collaborative qualitative study we explored how introducing translanguaging into a TESOL course originally designed as a SEI course impacted students' understandings of learning and teaching. We analyzed students' course work as well as our own experinces of being in the classroom. Thematic analysis showed there were some epistemic shifts that occurred among the students which seemed promising; these included: an understanding of language from a critical sociocultural perspective in relation to culture and identity; recognition of the benefits of multilingualism and multiculturalism; the goal of working towards justice for ELLs. However, we are not sure if the epistemic shifts we have observed will bring about pedagogical shifts in the students' actual teaching 
practices. Our future research aims to demonstrate how students both make sense of translanguaging theoretically and enact translanguaging in practice.

We recognize as researchers and teachers that we have much farther to travel in our process of exploring the possibilities of translanguaging. We must move from an approach that introduces translanguaging to one that integrates it. We must look more longitudinally at how students' understandings are translated into practice. We must also recognize that translanguaging is not the ultimate answer for improving language instruction. However, it is a beginning. We have learned that translanguaging opens up endless possibilities to challenge dominant structures, value the resources of all students, and work toward teaching for justice.

\section{References}

Bourdieu, P., \& Passeron, C. (1997). Reproduction in education, society and culture. (R. Nice, Trans.). London, UK: Sage.

Calderón, M., Slavin, R., \& Sánchez, M. (2011). Effective instruction for English learners. Future of Children, 21(1), 103-127.

Canagarajah, S. (2014). Translingual practice: Global Englishes and cosmopolitan relations. New York, NY: Routledge.

Cochran-Smith, M., \& Lytle, S. (1993). Inside/outside: Teacher research and knowledge. New York, NY: Teachers College Press.

Fairclough, N. (1989). Language and power. London, UK: Longman.

Foucault, M. (1980). Power/knowledge: Selected interviews and other writings, 1972-1977. New York, NY: Pantheon Books.

García, O. (2009). Bilingual education in the 21st century: A global perspective. Malden, MA: Wiley-Blackwell.

García, O. (2014). Countering the dual: Transglossia, dynamic bilingualism and translanguaging in education. In R. Rubdy \& L. Alsagoff (Eds.), The global-local interface, language choice and hybridity (pp. 100-118). Bristol, UK: Multilingual Matters.

García, O., Johnson, S., \& Seltzer, S. (2017). The translanguaging classroom:Leveraging student bilingualism for learning. Philadelphia, PA: Caslon.

García, O., \& Kleyn, T. (2016). Translanguaging with multilingual students: Learning from classroom moments. New York, NY: Routledge.

García, O., \& Leiva, C. (2014). Theorizing and enacting translanguaging for social justice. In A. Creese \& A. Blackledge (Eds.), Heteroglossia as practice and pedagogy (pp. 199-216). New York, NY: Springer.

García, O., \& Wei, L. (2014). Translanguaging: Language, bilingualism and education. New York, NY: Palgrave Macmillan.

Halsall, R., Carter, K., Curley, M., \& Perry, K. (1998). School improvement: The case for supported teacher research. Research Papers in Education: Policy and Practice, 13, 161-182.

Hubbard, R., \& Power, B. (1999) Living the questions: A guide for teacher-research. Portland, ME: Stenhouse.

Ladson-Billings, G. (2015). Just Justice [American Educational Research Association Social Justice in Education Award Lecture video]. Retrieved from https://www.youtube.com/watch?v=ofB t10TYhI

Lewis, C., \& Moje, E. B. (2003). Sociocultural perspectives meets critical theory: Producing knowledge through multiple frameworks. The International Journal of Learning, 10, 1980-1995.

Makalela, L. (2015). Moving out of linguistic boxes: The effects of translanguaging strategies for multilingual classrooms. Language and Education, 29(3), 200-217.

Makoni, S., \& Pennycook, A. (2007). Disinventing and reconstituting languages. In S. Makoni \& A. Pennycook (Eds.), Disinventing and reconstituting languages (pp. 1-41). Clevedon, UK: Multilingual Matters.

Martínez, R., Hikida, M., \& Durán, L. (2014). Unpacking ideologies of linguistic purism: How dual language teachers make sense of everyday translanguaging. International Multilingual Research Journal, 9(1), 26-42.

Orr, M., \& Annous, S. (2018). There is no alternative! Student perceptions of learning in a second Language in Lebanon. Journal of Language and Education, 4(1), 79-91.

Otheguy, R., García, O., \& Reid, W. (2015). Clarifying translanguaging and deconstructing named languages: A perspective from linguistics. Applied Linguistics Review, 6(3), 281-307.

Paris, D. (2012). Culturally sustaining pedagogy: A needed change in stance, terminology, and practice. Educational Researcher, 41(3), 93-97.

Pennycook, A. (2012). Language and mobility: Unexpected places. Bristol, UK: Multilingual Matters.

Ruiz, R. (1984). Orientations in language planning. NABE Journal, 8(2), 15-34.

Van Viegen Stille, S., Bethke, R., Bradley-Brown, J., Giberson, J., \& Hall, G. (2016). Broadening educational practice to include translanguaging: An outcome of educator inquiry into multilingual students' learning needs. The Canadian Modern Language Review / La Revue Canadienne des langues vivantes, 72(4), 480-503.

Vogel, S., \& García, O. (2017). Translanguaging. In G. Noblit (Ed.), Oxford research encyclopedia of education. Oxford, UK: Oxford University Press. 
Final Portfolio Requirements

\section{Appendix}

\section{Elements to be included in the portfolio:}

\section{1\&2. Title Page \& Table of Contents}

\section{Resume}

You could also include in this section any letters of reference or other professional documents.

\section{Philosophy of Language Statement}

This reflection should demonstrate your knowledge of language and its role in your field. I would like you to include educational theories, and strategies to support language learning/ language development. It should be personal and indicate what is most important to you that you learned in this class.

\section{Model Lesson Plan \& Reflection}

This section should include an introduction and rationale for your lesson plan/s. This should explain what you wanted to accomplish in your "lesson plan". Items to include in the plan itself: topic, grade level/ audience, number of students/ audience members, class/meeting time, media used, procedures, strategies used for supporting language development. At the end please include your own reflection assessing how the "lesson" went and what worked and what might be done differently.

\section{Reflection on Classroom Observation}

This should be a short reflection 1-3 pages that provides the following information: 1 . what class you observed (name/level/location), how many students, who was the professor, when was the class, etc. 2. An brief overview of what happened in the class 3. Strategies for working with ELLs that were used 4. What you learned or what "takeaways" you had

\section{Personal Reflection on the Needs Assessment and Language Service Proposal}

In this reflection I would like you to explain your own personal learning from interviewing students, working with your group and coming up with ideas for a language service. 